\title{
CONGENITAL HYDROCEPHALUS- AN EPIDEMIOLOGICAL STUDY OF MATERNAL CHARACTERISTICS IN A TERTIARY CARE CENTRE
}

\author{
Yogender Singh Kadian', Anjali Verma², Pradeep Kajal3, Nirmala Duhan ${ }^{4}$ \\ ${ }_{1}^{1}$ Professor, Department of Paediatric Surgery, Pt. B. D. Sharma PGIMS, Rohtak. \\ ${ }^{2}$ Assistant Professor, Department of Paediatrics, Pt. B. D. Sharma PGIMS, Rohtak. \\ ${ }^{3}$ Associate Professor, Department of Paediatric Surgery, Pt. B. D. Sharma PGIMS, Rohtak. \\ ${ }^{4}$ Professor, Department of Obstetrics and Gynaecology, Pt. B. D. Sharma PGIMS, Rohtak.
}

ABSTRACT
BACKGROUND
The epidemiology of congenital hydrocephalus is very unclear. Although various risk factors like maternal age, maternal illness and
child factors have been studied in the past, still there is a gap of knowledge regarding maternal risk factors associated in congenital
hydrocephalus in the literature.
The objective of the study is to measure risk factor proportions of mothers among the population of a tertiary care centre.

\section{MATERIALS AND METHODS}

A record-based, retrospective, descriptive study with secondary data analysis was done from the medical case records of women who delivered babies with congenital hydrocephalus from Jan. 2006 to Dec. 2016. Maternal epidemiological characteristics such as maternal age, parity, place of residence, educational status as well as birth characteristics were studied and analysed by using appropriate statistical methods.

\section{RESULTS}

A total of 123 babies were born with congenital hydrocephalus during the study period. Most mothers in the study were second gravida (56.91\%), rural based (74.79\%), women between 21-30 years (80.48\%) of age. Around 60.16\% women were educated up to $10^{\text {th }}$ grade and most (41.46\%) were homemakers. All but 5 women had vaginal births. Male babies were $52.03 \%$, and $64.78 \%$ babies weighed above $2 \mathrm{~kg}$ at birth.

\section{CONCLUSION}

Young women from rural areas of low literacy and bearing their second babies are more prone to deliver babies with congenital hydrocephalus.

\section{KEYWORDS}

Malformation, CSF, Maternal.

HOW TO CITE THIS ARTICLE: Kadian YS, Verma A, Kajal P, et al. Congenital hydrocephalus- An epidemiological study of maternal characteristics in a tertiary care centre. J. Evolution Med. Dent. Sci. 2017;6(75):5393-5396, DOI: 10.14260/Jemds/2017/1169

\section{BACKGROUND}

Congenital hydrocephalous is a birth defect characterised by accumulation of excess amount of cerebrospinal fluid (CSF) in the nervous system affecting around 1.1 per 1,000 infants. ${ }^{1}$ It results from the progressive expansion of the cerebral ventricles due to the deficient passage of CSF from the choroid plexus, the site of CSF synthesis, to its sites of absorption into the systemic circulation. ${ }^{2}$

This condition is caused by a complex interaction of various aetiological factors which are unclear till date. The disorder has far ranging physical, psychological and financial consequences for the affected baby and the family. Moreover, it may be associated with congenital malformations of the central nervous system, intracranial haemorrhage, infections and ingestion of potentially teratogenic pharmacological agents.

Financial or Other, Competing Interest: None.

Submission 08-08-2017, Peer Review 04-09-2017,

Acceptance 11-09-2017, Published 18-09-2017.

Corresponding Author:

Anjali Verma

H.No. 251,

Dev Colony,

Rohtak, Haryana.

E-mail: dranjali604@gmail.com

DOI: $10.14260 /$ jemds $/ 2017 / 1169$

\section{(c) $(7)$}

Several genetic and intrauterine factors may also contribute to the aetiology of this condition and around 5\% of all cases may be X-linked. ${ }^{3}$

The contribution of the maternal factors has not received much attention of researchers. Maternal febrile illness in the first trimester, maternal age $>35$ years, use of herbal medications, exposure to drugs, lack of use of periconceptional folic acid supplementation were the possible risk factors for various CNS anomalies especially neural tube defects, a closely related condition to hydrocephalus and these factors may impact the incidence of at least the congenital variety of hydrocephalus in any geographic area. ${ }^{4}$

The epidemiological characteristics of hydrocephalus are not well explored and understood. Although several previous epidemiological, clinical, and experimental studies assessing various individual risk factors for $\mathrm{CH}$ have been conducted, given the high complexity of this entity and its several potential aetiologies, a complex multifactorial (genetic and environmental) aetiology may be responsible for any or all subtypes of hydrocephalus. ${ }^{1,5}$ Given that $\mathrm{CH}$ is an important cause of serious infant health disability that can lead to health inequalities among adults, ${ }^{1}$ assessing and investigating extrinsic factors in the maternal environment that potentially confer an increased risk of $\mathrm{CH}$ development would be a crucial step in preventing some of these cases. Given the 
paucity of literature on this subject, the present study is an attempt to evaluate the maternal risk factors in the aetiology of congenital hydrocephalus.

\section{MATERIALS AND METHODS}

A record-based descriptive study was carried out by accessing and analysing the medical case records of women retrospectively who delivered babies with congenital hydrocephalus between Jan. 2006 to Dec. 2016 in the Department of Obstetrics and Gynaecology at a rural tertiary care centre in India. Diagnosis of hydrocephalus was made on clinical examination. Babies with head enlargement (head circumference $>=98^{\text {th }}$ percentile for age), wide open and tense fontanelle were included in our study. The total number of births in the study period was noted and various maternal epidemiological characteristics of babies born with congenital hydrocephalus like age, parity, place of residence, birth order, educational status, occupation were recorded from medical registers. Various obstetric parameters of pregnancies such as gestation at the time of diagnosis, presentation and mode of delivery were noted. Birth characteristics in the form of birth weight, sex of baby and the perinatal outcome were also recorded. Whole data was tabulated and analysed.

\section{RESULTS}

A total of 83,422 births took place during the study period of 11 years of which 123 babies had congenital hydrocephalus (1.47 per 1000 births). All but one were singleton pregnancies and only one of the twin babies of the solitary multiple gestation was affected by the disorder.

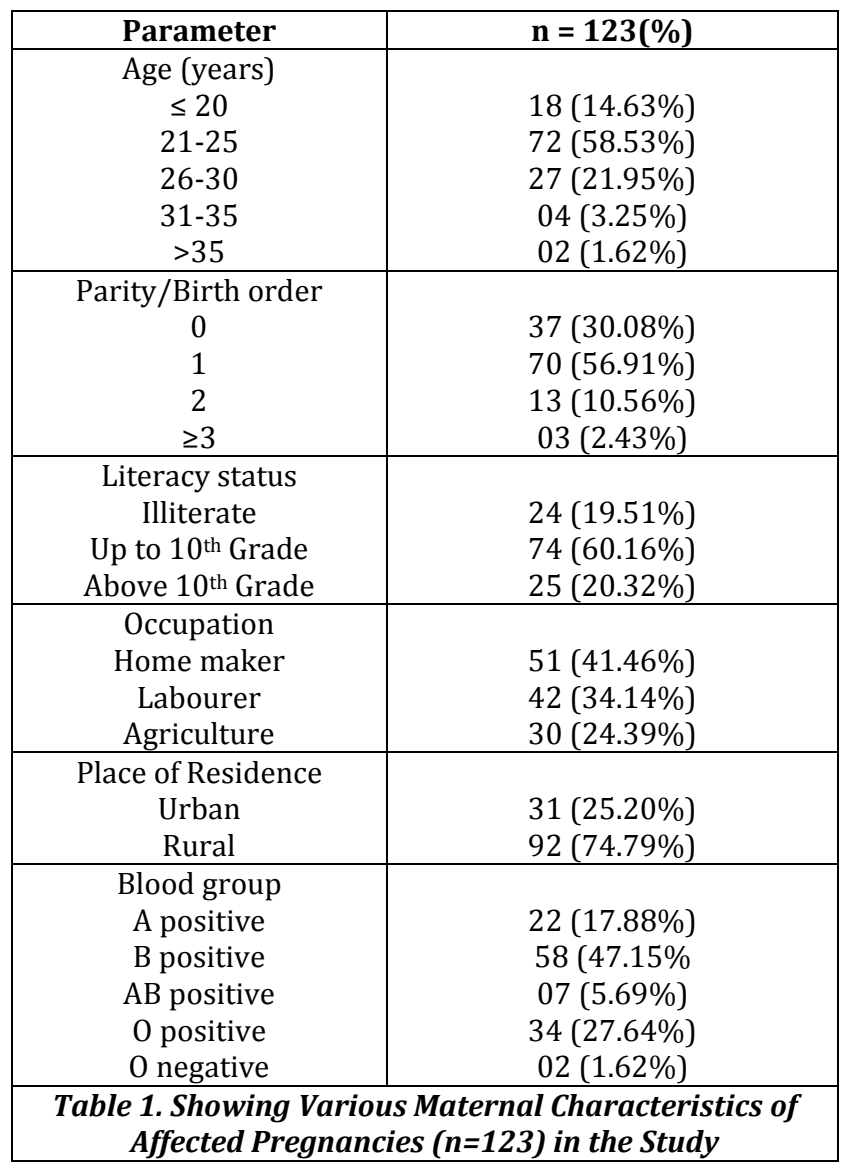

\begin{tabular}{|c|c|}
\hline Parameter & $\mathbf{n}=\mathbf{1 2 3}(\%)$ \\
\hline Gestation at presentation & $07(5.69 \%)$ \\
$2^{\text {nd }}$ trimester & $116(94.30 \%)$ \\
$3^{\text {rd }}$ trimester & $99(80.48 \%)$ \\
\hline Presentation & $23(17.88 \%)$ \\
Cephalic & $01(0.81 \%)$ \\
Breech & $74(60.16 \%)$ \\
Others & $44(35.17 \%)$ \\
Mode of delivery & $05(4.06 \%)$ \\
FTVD & PTVD \\
LSCS & wable 2. Showing Obstetric Parameters of Pregnancies \\
\hline \multicolumn{2}{|c|}{ with Congenital Hydrocephalus } \\
\hline
\end{tabular}

FTVD - Fullterm vaginal delivery.

PTVD - Preterm vaginal delivery.

LSCS - Lower segment caesarean section.

Table 1 depicts the various maternal characteristics while Table 2 shows the obstetric outcome in the study. High incidence of congenital hydrocephalus was seen in multipara females mainly of age group 21-25 years. Among other epidemiological features, most mothers were from rural background and mostly were either illiterate or educated up to $10^{\text {th }}$ grade. As is evident from Table 2, all but 5 newborns in the study were delivered vaginally. Of the five caesarean births, one each was carried out for placenta praevia, lower segment scar dehiscence, previous 2 caesarean sections, unwillingness for decompression of foetal head and foetal distress in an undiagnosed case. Another woman underwent hysterotomy and tubal ligation to deliver the hydrocephalic foetus as she had already two caesarean scars.

\begin{tabular}{|c|c|}
\hline Parameter & n = 123 (\%) \\
\hline Birth weight (kg) & $07(5.69 \%)$ \\
$0.5-1$ & $10(8.13 \%)$ \\
$1.01-1.50$ & $14(11.38 \%)$ \\
$1.51-2.0$ & $29(23.57 \%)$ \\
$2.01-2.50$ & $63(51.21) \%)$ \\
$\geq 2.51$ & $64(52.03 \%)$ \\
Sex & $59(47.96 \%)$ \\
Male & $63(51.21 \%)$ \\
Female & $59(47.96 \%)$ \\
Condition at birth & $01(0.81 \%)$ \\
Live & Fresh still birth \\
Macerated still birth & Table 3. Showing Neonatal Outcome in the Study \\
\hline \multicolumn{2}{|c|}{}
\end{tabular}

Table 3 shows the neonatal characteristics (birth weight, sex, condition at birth and associated anomalies) in the study. It is evident that a total of $74.68 \%$ of the newborns weighed over $2 \mathrm{~kg}$ at birth, around $80.48 \%$ presented as cephalic and that male babies outnumbered female neonates $(52.03 \%$ vs. $47.96 \%$ ). While $51.21 \%$ newborns were alive at birth, the remaining (47.96\%) were fresh stillborns.

\section{DISCUSSION}

Congenital hydrocephalus is a serious condition that can arise from multiple causes. It comprises a diverse group of conditions which result in impaired circulation and absorption of cerebrospinal fluid. Congenital malformations of the central nervous system, infections, haemorrhage, 
trauma, teratogens and occasionally, tumours can all give rise to hydrocephalus.

Hydrocephalus is said to be congenital when no extrinsic cause is noted to contribute to its aetiology. Congenital hydrocephalus may be syndromic with a recognisable genetic basis or a clinical syndrome and the syndromic variety may or may not be associated with other major congenital abnormalities. In either case, the treatment commonly involves a prolonged multidisciplinary approach with wide ranging implications from financial to those affecting quality of life and mortality. Very sparse literature is available on the maternal environmental risk factors for this condition.

Incidence of hydrocephalus in our study was 1.47:1000 live births which is relatively higher than data from other Indian study. ${ }^{6}$ No definite relationship of congenital hydrocephalus with maternal age has been reported by most researchers except a cross sectional retrospective study conducted in Enugu, Nigeria which showed increased incidence of CNS anomalies in mothers $>35$ years of age. ${ }^{4}$ Some other studies have also shown that a direct relationship exists between maternal age and incidence of congenital anomalies and showing that a higher incidence has been reported in elderly primiparous mothers and low incidence with age $<20$ years.6,7 A higher delivery rate in younger women may have contributed to the higher incidence of the condition in the present study. Parity has not been shown to be an important risk factor. However, a higher incidence in lower birth orders in our study is evident and a higher incidence in firstborns has been reported by Munch et al. ${ }^{8}$ Women with low literacy, rural residence and homemakers appear to be more at risk of congenital hydrocephalus. These factors may be interrelated as rural areas offer limited opportunities for education and employment. As ours is a rural based study, antenatally very few cases were detected as a result of ignorance and non-availability of proper antenatal services in the periphery. Moreover, wide gender disparities are common in rural Indian societies which further limit not only the work opportunities but also decision making of these underprivileged women. Munch et al also observed homemakers to be at increased risk of congenital hydrocephalus. ${ }^{8}$

Kalyvas et al analysed 13 studies to evaluate various environmental risk factors in development of congenital hydrocephalus and reported lack of prenatal care and low socioeconomic status were significantly associated with the condition. The systematic review showed that complete lack of prenatal care is strongly associated with $\mathrm{CH}$ specifically and initiating prenatal care after the $8^{\text {th }}$ month of gestation is also related to the development of $\mathrm{CH} .{ }^{9}$ The present study highlights the lack of prenatal care in women bearing babies with congenital hydrocephalus. It is apparent from our study that most $(94.30 \%)$ of these women presented in third trimester when the foetal condition was diagnosed. Although Munch et al have reported that preterm births at less than 28 weeks of gestation are at higher risk, the condition is more likely to present late in pregnancy or in labour in women with late onset of antenatal care or in its total absence. ${ }^{8}$ Total lack of antenatal care has been shown to be strongly associated with development of congenital hydrocephalus by Landingham et al. ${ }^{5}$ Lack of early prenatal care, which is significantly associated with congenital hydrocephalus, may represent a general indicator of the social environment indirectly affecting maternal behavioural and exposure patterns rather than a mechanistic factor. In this context, it is noteworthy that a low socioeconomic status has been shown to significantly increase the risk of $\mathrm{CH}$ by a large cohort study. ${ }^{10}$ Similarly, the late initiation of prenatal care after $8^{\text {th }}$ month of pregnancy was found to be closely associated with higher incidence of the condition by Carnichael et al.11 Late pregnancy is associated with higher complication rate than early pregnancy. A late diagnosis of the condition further increases the risk of complications like polyhydramnios, preeclampsia, anaemia, increased operative interference, postpartum haemorrhage and a higher morbidity and mortality, especially in a low resource setting. In addition, the psychological impact of delivery of a majorly compromised neonate on the parents cannot be underestimated. On the other hand, the anomaly scan may not accurately detect the condition given the fact that ventricular dilatation in affected cases commonly begins after 20 weeks of gestation. ${ }^{3}$

Regarding perinatal outcome, there is predominance of males with congenital hydrocephalus which is concordant with other studies ${ }^{8}$ and prognosis was also poor. The condition of the baby at birth depends on several factors like gestation, birth weight, degree of hydrocephalus and presence/absence of associated anomalies. Garne et al analysed data of congenital hydrocephalus from four European Registries of Congenital Malformations (EUROCAT) for the period 1996-2003, after excluding cases of congenital hydrocephalus with coexisting neural tube defects. ${ }^{12}$ They concluded that a high proportion of such pregnancies are terminated in view of severe anomaly and among the live borns too, the mortality is high. Lorber in his longitudinal study on the family history of 270 babies with uncomplicated hydrocephalus suggested that the aetiology of congenital hydrocephalus and neural tube defects is probably related.13

The main limitation of our study is that we have not compared our cases with controls in the study population as ours is a record-based study, hence some confounding factors are present in the study. It should be noted that a complex multifactorial (Genetic and environmental) aetiology has been proposed as the basis for any or all subtypes of $\mathrm{CH}^{1,5}$ and that genetic screening in patients with $\mathrm{CH}$ is typically initiated in the presence of major concurrent clinical findings. ${ }^{1}$ Hence, findings should be interpreted cautiously and regarded as possible future avenues of research under epidemiological, clinical, and preclinical settings. ${ }^{9,14,15,16}$

\section{CONCLUSION}

First or second pregnancies of young, illiterate women from rural background are more prone to congenital hydrocephalus. Even though a genetic basis has been speculated, most of the causative factors still remain unclear for this disorder which has wide ranging health and financial implications for the affected individuals and their families. Larger studies evaluating the predisposition, diagnosis and management of the condition in early gestation are warranted.

\section{REFERENCES}

[1] Tully HM, Dobyns WB. Infantile hydrocephalus: a review of epidemiology, classification and causes. Eur J Med Genet 2014;57(8):359-68. 
[2] Rekate HL. The definition and classification of hydrocephalus: a personal recommendation to stimulate debate. Cerebrospinal Fluid Res 2008;5:2.

[3] Schrander-Stumpel C, Fryns JP. Congenital hydrocephalus: nosology and guidelines for clinical approach and genetic counselling. Eur J Pediatr 1998;157(5):355-62.

[4] Eke CB, Uche E0, Chinawa JM, et al. Epidemiology of congenital anomalies of the central nervous system in children in Enugu, Nigeria: a retrospective study. Ann Afr Med 2016;15(3):126-32.

[5] Van Landingham M, Nguyen TV, Roberts A, et al. Risk factors of congenital hydrocephalus: a 10 year retrospective study. J Neurol Neurosurg Psychiatry 2009;80(2):213-7.

[6] Venkataramana NK. Hydrocephalus Indian scenario -a review. J Pediatr Neurosci 2011;6(Suppl 1):S11-S22.

[7] Mohamed A, Mohamed M, Ahmed E, et al. Dysmorphogenesis, clinical study. Assiut University (Egypt) Medical Journal 2007;30:159-84.

[8] Munch TN, Rasmussen ML, Wohlfahrt J, et al. Risk factors for congenital hydrocephalus: a nationwide, register-based, cohort study. J Neurol Neurosurg Psychiatry 2014;85(11):1253-9.

[9] Kalyvas AV, Kalamatianos T, Pantazi M, et al. Maternal environmental risk factors for congenital hydrocephalus: a systematic review. Neurosurg Focus 2016;41(5):E3.
[10] Jeng S, Gupta N, Wrensch M, et al. Prevalence of congenital hydrocephalus in California, 1991-2000. Pediatr Neurol 2011;45(2):67-71.

[11] Carmichael SL, Shaw GM, Nelson V. Timing of prenatal care initiation and risk of congenital malformations. Teratology 2002;66(6):326-30.

[12] Garne E, Loane M, Addor MC, et al. Congenital hydrocephalus--prevalence, prenatal diagnosis and outcome of pregnancy in four European regions. Eur J Paediatr Neurol 2010;14(2):150-5.

[13] Lorber J. The family history of "simple" congenital hydrocephalus. An epidemiological study based on 270 probands. Z Kinderchir 1984;39(Suppl 2):94-5.

[14] Adeloye A, Warkany J. Experimental congenital hydrocephalus. A review with special consideration of hydrocephalus produced by zinc deficiency. Childs Brain 1976;2(6):325-60.

[15] Hyoun SC, Običan SG, Scialli AR. Teratogen update: methotrexate. Birth Defects Res A Clin Mol Teratol 2012;94(4):187-207.

[16] Olivier JD, Blom T, Arentsen T, et al. The agedependent effects of selective serotonin reuptake inhibitors in humans and rodents: a review. Prog Neuropsychopharmacol Biol Psychiatry 2011;35(6):1400-8. 